\title{
A aposentadoria na perspectiva ocupacional: continuidade do curso de vida e novas possibilidades
}

\section{Retirement from the occupational perspective: continuity of the life course and new possibilities}

\author{
Cecília Melo Neves Xavier ${ }^{1}$, Kátia Maria Penido Bueno ${ }^{2}$, Luciana de Oliveira \\ Assis $^{2}$, Simone Costa de Almeida ${ }^{2}$, Marcella Guimarães Assis $^{3}$
}

http://dx.doi.org/10.11606/issn.2238-6149.v28i2p214-220

\begin{abstract}
Xavier CMN, Bueno KMP, Assis LO, Almeida SC, Assis MG. A aposentadoria na perspectiva ocupacional: continuidade do curso de vida e novas possibilidades. Rev Ter Ocup Univ São Paulo. 2017 maio-ago.;28(2):214-20.
\end{abstract}

RESUMO: O aumento da expectativa de vida contribui para que aposentados estejam envolvidos em ocupações por muitos anos, o que demanda a criação de novos arranjos ocupacionais para suas vidas. Percebe-se uma ausência, na literatura, da compreensão do modo como o sujeito acessa as ocupações que constituirão a nova rotina. Esse trabalho objetiva compreender, a partir da percepção do aposentado, como as ocupações realizadas no percurso de vida participam da reorganização ocupacional na aposentadoria. Tratase de estudo qualitativo, fundamentado teoricamente no paradigma de desenvolvimento ao longo de toda a vida (life span). Os dados foram coletados por meio de entrevistas semi-estruturadas com 30 idosos. Os resultados foram analisados por análise de conteúdo e foram apresentados em quatro categorias: ao longo de toda a vida; antigos significados, novas ocupações; agora eu posso; outras possibilidades: a descoberta. Os resultados revelaram que ocupações realizadas no percurso de vida são referências importantes na aposentadoria, ressaltando a relevância da história ocupacional. Identificou-se também a prática de novas ocupações, comprovando que esse pode ser um momento de novas possibilidades. Este estudo não incluiu diferenciações quanto ao gênero e classe social e tais aspectos poderão ser abordados em estudos futuros.

DESCRITORES: Aposentadoria; Idoso; Ocupações.
Xavier CMN, Bueno KMP, Assis LO, Almeida SC, Assis MG. Retirement from the occupational perspective: continuity of the life course and new possibilities. Rev Ter Ocup Univ São Paulo. 2017 May-Aug.;28(2):214-20.

ABSTRACT: Increased life expectancy contributes to retirees being involved in occupations for many years, which requires the creation of new occupational arrangements for their lives. In literature there is a lack of information on how subjects access the occupations that will be part of their new routine. This work aims to understand how the occupations performed in the retirees' life course participate in occupational reorganization in retirement, from their perspective. This is a qualitative study, theoretically based on the life span development paradigm. Data were collected through semi-structured interviews with 30 older adults. The results were analyzed by content analysis and presented in four categories: Throughout life; Old meanings, new occupations; Now I can; Other possibilities: the discovery. The results showed that occupations carried on throughout the life course are important references in retirement, highlighting the importance of occupational history. Practicing new occupations was also identified, proving that this time can be a time of new possibilities. This study, being restricted to one country, does not include differences according to gender or social class, and such aspects may be addressed in future studies.

KEYWORDS: Retirement; Aged; Occupations.

Esse artigo é parte integrante de dissertação do Programa de Pós Graduação em Ciências da Reabilitação, Universidade Federal de Minas Gerais.

1. Mestre pelo Programa de Pós Graduação em Ciências da Reabilitação, Universidade Federal de Minas Gerais. E-mail: ceciliaxavierto@gmail.com

2. Professora Adjunta do Departamento de Terapia Ocupacional, Universidade Federal de Minas Gerais. E-mail: katiapenidobueno@ gmail.com, luoliveira.ufmg@gmail.com, salmeida@ufmg.br

3. Professora Titular do Departamento de Terapia Ocupacional, Programa de Pós Graduação em Ciências da Reabilitação, Universidade Federal de Minas Gerais. E-mail: mga@ufmg.br

Endereço para correspondência: Marcella Guimarães Assis. Departamento de Terapia Ocupacional. Escola de Educação Física, Fisioterapia e Terapia Ocupacional. Av. Antônio Carlos, 6627. Pampulha, Belo Horizonte, MG. CEP: 31270-901. 


\section{INTRODUÇÃO}

$\mathrm{O}$ desenvolvimento humano pode ser compreendido como um fenômeno dinâmico, heterogêneo e contextualizado que ocorre ao longo de toda a vida - paradigma do life span $^{1}$ - portanto, não se restringe a um único período etário. Para a compreensão do desenvolvimento, esse paradigma considera, entre outros elementos, as situações vividas subjetivamente, as dinâmicas intergeracionais, assim como as mudanças no contexto histórico dos indivíduos ${ }^{1}$.

Nas variadas fases do desenvolvimento, as ocupações se diversificam e possuem um papel importante sobre a criação e experimentação de um sentido vital, o que faz do homem um ser ocupacional ${ }^{2}$. Elas participam da construção de um estilo de vida equilibrado e funcional ${ }^{3}$. É por intermédio de ocupações exercidas que o homem marca a sua existência ${ }^{4}$.

Christiansen e Townsend ${ }^{2}$ argumentam que estar ocupado significa usar e assumir o controle do tempo e do espaço como pessoa engajada na vida. $\mathrm{Na}$ fase adulta, dentre as ocupações que compõem o repertório ocupacional humano, o trabalho merece especial atenção, podendo ser considerado um dos principais organizadores da vida e estruturador do dia a dia das pessoas. Ele ocupa espaço inegável na existência humana ${ }^{5}$ funcionando como um organizador da estrutura de tempo (dias, meses, anos); divisor entre atividades pessoais e impessoais; definidor de diferentes fases da vida (estudo, trabalho e aposentadoria) e ainda é responsável por grande parte das horas produtivas do cotidiano, pelo desenvolvimento de habilidades e reconhecimento social ${ }^{6}$. Para Lancman ${ }^{7}$, o trabalho é um elemento de suma importância na construção da saúde das pessoas.

Assim, a interrupção do trabalho pode determinar uma mudança importante nos padrões de desempenho pessoais, afetando diretamente a rotina, os hábitos e os papéis sociais ${ }^{8}$ e interferindo significativamente na organização ocupacional dos indivíduos. Frequentemente, essa ruptura se dá pela chegada da aposentadoria, fenômeno que, embora previsível ${ }^{9}$, será enfrentado de diversas maneiras pelos indivíduos ${ }^{10-12}$. Durante muito tempo, a aposentadoria foi compreendida como o momento de tomada de decisão em que a pessoa faz uma escolha motivada a diminuir seu compromisso com as atividades relacionadas ao trabalho. Porém, a aposentadoria também pode ser conceituada como um processo de ajuste que inclui tanto o momento de deixar o emprego, quanto à trajetória pós-aposentadoria ${ }^{13}$.
Estudos realizados com idosos encontraram certos pontos comuns na forma como esses sujeitos enfrentam a vida sem o trabalho, identificando fatores que participam deste processo de adaptação, tais como a história laboral, o contexto social e de lazer, o nível socioeconômico, a relação familiar e as crenças religiosas ${ }^{10,11,14}$.

Nesse sentido, o envolvimento em atividades e ocupações significativas é um elemento facilitador da adaptação à aposentadoria e da manutenção da saúde ${ }^{8,11}$. No processo de organização de uma nova combinação ocupacional que preencha o tempo livre com significado, Jonsson et al. ${ }^{15,16,17}$ ressaltam que algumas ocupações, especificamente aquelas ditas engajadas e sociais, são mais favoráveis à conquista de uma vida com qualidade. Compreendem-se como ocupações engajadas aquelas com alto nível de significado, que geram compromisso ou responsabilidade social e demandam participação intensa o que inclui o tempo gasto e a regularidade na sua realização. Por estas razões, os sujeitos pesquisados no estudo citado atribuíram grande destaque às ocupações engajadas que exercem papel de liderança, conectando pessoas que compartilham interesses comuns e proporcionando identidade ao indivíduo ${ }^{17}$. Porém, inexistindo as ocupações engajadas, elas podem ser substituídas por aquelas ditas sociais, que se referem ao contato com pessoas da família como cônjuge, filhos, netos, bem como amigos e outras pessoas da comunidade ${ }^{16}$. Segundo a classificação de Jonsson $^{16}$, além das ocupações engajadas e sociais, existem aquelas denominadas: relaxante, básica, regular, irregular e para matar o tempo. A ocupação relaxante é considerada como merecida e agradável, mas parece não possuir tanta importância quando a ocupação engajada está ausente. Entende-se que só é preciso relaxar quando se faz algo para se cansar. A ocupação básica é ligada ao "ter que fazer" como hábito ou parte da rotina para satisfazer as necessidades diárias como alimentação, sono, higiene pessoal entre outras. A ocupação regular é realizada com regularidade, ainda que uma vez por mês ou por semana, mas não necessariamente gerando envolvimento com o que se está fazendo, como por exemplo, caminhadas para manter a saúde. A ocupação irregular é praticada vez ou outra porque se identifica nela um sentido positivo. Viajar, ir ao cinema ou ao teatro são alguns exemplos. A ocupação para matar o tempo existe pela necessidade humana de estar ocupado - na ausência de algo que gere envolvimento e significado, recorre-se a ela.

Com o acelerado envelhecimento populacional e o aumento da expectativa de vida as pessoas que se aposentam têm condições de se manter envolvidas em ocupações por mais 20 ou 30 anos $^{11,15}$, podendo tornar 
a fase pós-aposentadoria a parte mais longa da vida adulta. Assim, os aposentados precisarão criar uma nova combinação ocupacional para suas vidas ao longo de todo esse tempo, sendo relevante conhecer quais ocupações estes sujeitos buscarão a partir da ruptura com a rotina guiada pelo trabalho. Dessa forma, o objetivo deste estudo é compreender e discutir, a partir da percepção da pessoa idosa aposentada, o modo como as ocupações realizadas no percurso de vida participam do processo de reorganização das ocupações na aposentadoria e no longo período que pode se seguir a ela.

\section{PERCURSO METODOLÓGICO}

O desenho metodológico qualitativo foi escolhido por permitir a identificação das percepções e dos significados atribuídos pelos próprios idosos às ocupações que realizaram em fases anteriores da vida e as que realizam na aposentadoria. $\mathrm{O}$ enfoque teórico que embasa a análise e discussão dos resultados é o paradigma do life span que aborda o desenvolvimento como um processo dinâmico e permanente durante o curso de vida.

\section{Participantes}

Com objetivo de homogeneizar a amostra em relação a um período do desenvolvimento, tendo como referência o paradigma Life Span, foram, selecionados por conveniência, participantes idosos, com no mínimo sessenta anos de idade. Segundo Robson ${ }^{18}$, esse método permite a identificação dos participantes que apresentam as características necessárias para a investigação do que se propõe. Foram critérios de inclusão: estarem aposentados há no mínimo 3 anos e, no máximo, 10, serem de ambos os sexos e com níveis de escolaridade e socioeconômicos variados. Este tempo mínimo de aposentadoria foi estabelecido para que cada participante tivesse um tempo suficiente de experiência neste novo cenário ${ }^{19}$. O tempo máximo foi determinado para não se perder a clareza necessária das memórias dos últimos anos. $\mathrm{O}$ número de sujeitos entrevistados foi definido por saturação ${ }^{20}$. Foram excluídos do estudo idosos que retomaram alguma atividade de trabalho remunerado e regular após a aposentadoria e aqueles com comprometimentos cognitivos, mentais, de linguagem ou sensoriais, incapacidades físicas adquiridas após a aposentadoria, ou qualquer doença que pudesse reduzir sua capacidade de execução das atividades cotidianas e ou as condições de comunicação. Os nomes usados no estudo são fictícios para preservar a privacidade dos participantes e o sigilo foi acordado entre o entrevistado e o pesquisador.

\section{Coleta e análise dos dados}

Este estudo utilizou entrevistas semi-estruturadas, cujas perguntas abordaram a história profissional dos participantes e a relação deles com o trabalho, as ocupações realizadas para além da atividade laboral no passado, a maneira como se deu o processo de transição para a aposentadoria, como ficou a nova rotina com relação às ocupações e, por fim, a possível relação entre o que faziam anteriormente, além do trabalho, e o que fazem no presente como aposentados.

Um projeto piloto foi realizado para verificar a adequação das perguntas e da linguagem utilizada.

O estudo foi iniciado após análise e aprovação do projeto pelo Comitê de Ética em Pesquisa da Universidade Federal de Minas Gerais (CAAE -13849413.5.0000.5149). Os entrevistados tiveram participação voluntária na pesquisa e assinaram o Termo de Consentimento Livre e Esclarecido (TCLE). O contato para agendamento das entrevistas foi realizado por telefone. A duração das mesmas variou entre 20 e 66 minutos, totalizando 19 horas e 46 minutos de gravação. Todas as entrevistas foram realizadas em condições favoráveis para a coleta dos dados - nas residências dos participantes, em horário e dia de escolha dos mesmos, gravadas em equipamento digital com uso de microfone para melhor qualidade do áudio e integralmente transcritas para posterior análise. As transcrições foram encaminhadas aos participantes para confirmação do conteúdo apresentado.

Em seguida, os dados coletados foram avaliados, utilizando-se análise de conteúdo na modalidade de análise temática ${ }^{20}$ que, por sua vez, é constituída por três fases. A primeira, considerada como pré-análise, foi composta pela leitura flutuante do corpus. Em seguida foram realizadas leituras exploratórias exaustivas para retomada dos objetivos iniciais da pesquisa e percepção dos primeiros indicadores para compreensão dos dados. A segunda, dedicada à exploração do material, momento da formação das categorias e, a terceira, para tratamento dos resultados obtidos e interpretação ${ }^{20}$.

\section{RESULTADOS E DISCUSSÃO}

Foram entrevistados sete homens e 23 mulheres de 60 a 73 anos. A média das idades foi de 65,4 anos e o tempo de aposentadoria variou entre três e sete anos. Em relação à escolaridade, 13 cursaram até o ensino fundamental; quatro, o ensino médio e 13 concluíram o nível superior, enquanto a faixa de renda dos entrevistados foi ampla e esteve compreendida entre um a mais de 20 salários mínimos mensais. Com relação ao estado civil, cinco eram solteiros, 
seis viúvos e 19 casados. Quatro se aposentaram por idade, 17 por tempo de serviço e nove por tempo de serviço e idade. Quanto à relação com o trabalho, 19 participantes relataram uma experiência positiva, três, uma experiência negativa e sete uma relação tanto positiva quanto negativa.

A partir da análise das entrevistas, considerando o conjunto das ocupações realizadas no curso e vida e suas relações com os períodos de pré e pós-aposentadoria, quatro categorias emergiram: Por toda a vida; Antigos significados, novas ocupações; Agora eu posso; Outras possibilidades: a descoberta.

\section{Por toda a vida}

Nesta categoria, os entrevistados referem-se a algumas ocupações que os acompanham por muitos anos ou ao longo de toda a vida. Duas entrevistadas relatam suas experiências. A primeira diz:

Eu comecei a bordar, era pequena, tinha uns seis, sete anos, minha mãe bordava muito. [...] Eu aprendi pequenininha e mexo com isso até hoje (Irene, 66 anos).

Outra senhora explica:

Antes de aposentar eu já fazia, [produção de sabão] desde quando eu descobri que podia aproveitar aquele óleo comecei a fazer [sabão]. [...] só compro sabão para lavar roupa [...] na máquina (Izabela, 67 anos).

As experiências com esse tipo de continuidade ocupacional apareceram com grande intensidade e relevância nos dados analisados.

$\mathrm{Na}$ dinâmica do cotidiano em que é imensa a variedade de atividades e ocupações que preenche a rotina, variando nas diferentes fases da vida, é interessante observar que algumas delas resistem às vicissitudes e permanecem com grande durabilidade na história dos sujeitos, sem interrupção, como informa este senhor:

Toda vida eu fui ao cinema e encontrei com os amigos no final de semana, pra tomar uma cerveja. Eu sempre fiz e continuo fazendo a mesma coisa, né? Isso ai não mudou nada! (Paulo, 71 anos).

Dessa forma, as ocupações compõem um estilo de vida, participam e formatam nossas identidades pessoais, sociais e culturais ${ }^{2}$. Considerando-se que a pessoa atravessou episódios importantes da sua história sem interromper a execução de determinada ocupação, imagina-se que essa passe a ser constitutiva da identidade do sujeito ${ }^{2}$. De tal modo que, quando enfrentamos uma situação de mudança significativa - como a aposentadoria, considerada uma das maiores e mais abruptas transições ocupacionais vivenciadas ${ }^{9}$ - as ocupações podem ser apoios e referências no momento desta adaptação quando, espontaneamente, recorremos aos recursos armazenados na trajetória da nossa história. Zanelli e Silva ${ }^{21}$ sugerem que as atividades realizadas no percurso de vida tornam-se sólidos parâmetros em situações futuras. Pode-se dizer, que o que se faz por vontade própria, regularmente, com grande dedicação de tempo e que se desdobra em outras ocupações carrega tamanha riqueza e significado que ganha um destaque no conjunto das ocupações realizadas. Dessa forma pode-se pensar que estar em contato com uma mesma ocupação por longos anos implica em grande dedicação e envolvimento com a mesma, características que fazem com que as ocupações encontradas nesta categoria possam ser consideradas engajadas ${ }^{16}$.

\section{Antigos significados, novas ocupações}

Diferentemente da primeira categoria, o que perdura aqui é o significado da ocupação, e não a sua realização, como registra esta mulher:

Eu falei assim: [...] eu quero trabalhar com pessoas. Ai por isso que eu parti para enfermagem [...] (Taiz, 64 anos). Quanto à aposentadoria, a entrevistada prossegue em seu relato. [...] hoje eu estou concentrando minhas energias em ajudar minha filha que teve neném [...] eu vou lá de manhã, dou banho no neném [...]. Arrumo as coisinhas dela, deixo tudo organizado, vejo como ela está, ai eu venho embora [...] fico lá o tempo que ela precisa [...].

Percebe-se, portanto, que a experiência do cuidado foi mantida, tornando-se a conexão que atravessa diferentes ocupações na vida da entrevistada. Em um primeiro momento, a profissão de Enfermagem e na aposentadoria, o cuidado com a neta. Contudo, observa-se uma reorganização mais complexa do que simplesmente a presença da mesma ocupação na vida do sujeito, pois ao mesmo tempo há um elemento de permanência, no caso, o cuidado, - mantendo o significado - mas não a atividade propriamente dita.

De forma semelhante, outro entrevistado expressa a mesma relação de permanência de significado e mudança da ocupação.

Eu fui conselheiro do CREA, diretor de Sindicato $e$ ajudei a criar a associação dos funcionários [...], que é uma atividade mais política [...] (Marcelo, 63 anos). 
No momento pós-aposentadoria, ele se envolve com a defesa do meio ambiente do lugar onde vive.

Essa questão das atividades da comissão em defesa do patrimônio e meio ambiente do condomínio. [...] é uma atividade politica [...] porque tem articulação com os movimentos...

Portanto, diante de um amplo leque de possibilidades ocupacionais que a cultura e a sociedade oferecem, o indivíduo faz escolhas em que estão implícitos seus interesses, suas habilidades e significados ocupacionais. Percebe-se, assim, que outras atividades podem estar relacionadas àquilo que a pessoa realizou antes do evento da aposentadoria ${ }^{21}$, ou seja, embora a ocupação deixe de ser realizada, o sujeito transfere o seu significado para outra. Assim, esses significados ocupacionais sustentam a nova rotina, o que evidencia o desejo de preservar a vivência anterior e a novidade para este momento da vida.

\section{Agora eu posso!}

Duas mulheres descrevem a sensação de liberdade experimentada com a aposentadoria:

a única coisa que eu queria fazer [...] quando eu aposentasse, era ter tempo para mim, para fazer academia, hidroginástica, caminhada... a gente não tinha tempo, né? Então eu faço tudo isso [...] Quando eu aposentei eu fiquei igual um passarinho (Helena, 63 anos).

[...] eu começava mas não tinha tempo de estudar inglês. Eu não tinha, até então, muito tempo para pensar em outra coisa [...] na segunda-feira, agora, eu tenho aula de inglês [...] (Luiza, 62 anos).

Aqui se percebe que o tempo livre adquirido é um elemento que possibilita o (re)encontro com ocupações exercidas ou desejadas, mas não praticadas continuamente em função da rotina mais limitante, intensamente dedicada ao trabalho. Possivelmente, uma ocupação retomada em momento futuro indique significados relevantes para o sujeito. Afinal, as atividades realizadas no percurso da vida constroem um repertório de competências no aposentado que pode ser utilizado em outra fase, em um diferente contexto ${ }^{14}$.

Independentemente da forma como a aposentadoria é vivida, uma consequência inevitável é a mudança no modo de se utilizar o tempo ${ }^{22}$. Para Alvarado et $\mathrm{al}^{8}{ }^{8}$, romper com o trabalho é mover-se do tempo completamente preenchido para uma rotina aberta, com possibilidades de encontrar ocupações que gerem bem estar ${ }^{14}$. Pettican e Prior $^{23}$ também evidenciaram uma intensificação da realização de ocupações prazerosas em função da diminuição das responsabilidades ligadas ao trabalho. Ou seja, o aposentado vive uma situação de ampliação do tempo livre e, nesse contexto, pode retornar a antigas referências ocupacionais impossibilitadas de serem mantidas naquela época e colocá-las em prática. A centralidade do trabalho no período pré-aposentadoria, pode levar a interrupção de algumas ocupações prazerosas resultando em uma lista de desejos possíveis de serem realizados na nova estrutura temporal mais flexível da aposentadoria.

Quando as pessoas querem reorientar suas vidas durante grandes transições como a aposentadoria, suas histórias as direcionam de forma a conectar passado, presente e futuro ${ }^{12}$. Neste trabalho, as três categorias anteriores indicam um sentido de continuidade das ocupações experimentado de formas diferentes. A continuidade da mesma ocupação sem interrupção ao longo da vida é encontrada na primeira categoria. Diferentemente, na segunda, a continuidade se manifesta na prevalência do significado e, na terceira, no resgate de uma ocupação que foi interrompida ou não pôde ser exercida anteriormente pela falta de tempo.

Independentemente de suas variações, as três categorias acompanham as premissas do paradigma life span. Elas explicitam o movimento presente na aposentadoria e evidenciam que o desenvolvimento é um processo contínuo, heterogêneo e contextualizado ${ }^{1}$. Neste estudo, temos uma diversidade de ocupações realizadas pelos aposentados. Cada um, dentro do seu contexto, recriou um novo arranjo ocupacional. Cabe ressaltar, no entanto, que a amostra deste estudo foi constituída por idosos com idades entre 60 e 73 anos, que se encontravam na velhice inicial. Esses achados não podem ser estendidos para idosos muito idosos, visto que os autores Baltes e Smith ${ }^{1}$ questionam até que ponto as aplicações dos propósitos do paradigma life span se mantem sustentáveis para a velhice avançada, tendo em vista as perdas funcionais acumuladas.

\section{Outras possibilidades: a descoberta}

A quarta categoria põe em destaque o potencial de construção permanente do desenvolvimento a partir de novos elementos, como ilustra o relato desta mulher: 
Ah, porque...igual jogar bingo, eu nunca tinha jogado! Agora até que eu gosto de jogar. Eu participo (Elizabeth, 65 anos).

A aposentadoria pode ser não apenas uma fase de continuidade das referências construídas ao longo da vida, mas também de efetiva abertura para o novo.

Hoje é bom caminhar, é a melhor coisa que tem. Não faz parte daquilo que eu fazia! Antigamente, antes de aposentar, eu não andava não. Só comecei a andar depois eu me aposentei (Leonardo, 71 anos).

Percebe-se uma ruptura com o formato de continuidade e o aparecimento de ocupações inéditas. As mudanças que se dão na forma como as ocupações se organizam a partir do rompimento com o trabalho podem trazer outros interesses e possibilidades de ocupações não realizadas ou imaginadas anteriormente ${ }^{17}$. Para Zanelli ${ }^{14}$ é um período propício a descobertas e aprendizados sobre si e sobre o mundo, intensificando o desenvolvimento pessoal. Novos projetos podem ser criados e colocados em prática, mantendo-se a rotina preenchida e com significado.

A fase da aposentadoria pode significar para alguns um período de retraimento de significados; para outros, uma oportunidade de novas conquistas ${ }^{14}$, despertando reações variadas, embora para todos haja a necessidade de um rearranjo ocupacional. Silva ${ }^{24}$ expressa que, surge, para os aposentados, a demanda pela criação e execução de novos projetos de vida, para que esse tempo que se coloca à disposição não se transforme em vazio desmotivador.

Os relatos expressaram, em todas as categorias nas quais foram agrupados, a propensão das pessoas de darem sequência ao que desenvolviam antes da aposentadoria ou, ainda, para criação de um diferente contexto ocupacional, comprovando o potencial humano de iniciar algo novo em qualquer época da vida ${ }^{4}$. Os entrevistados explicitaram que o desenvolvimento não está restrito às fases mais precoces, que não se conclui na velhice, mas se estende por todo o curso de vida, como postulado no paradigma life $\operatorname{span}^{25}$. Tal paradigma considera as conexões entre eventos e processos anteriores e posteriores. A teoria do desenvolvimento ao longo de toda a vida, assim como os resultados encontrados nesta pesquisa, confirmam que pode haver movimento e crescimento na velhice, levando a novos aprendizados e aquisições em momentos de transição e de ruptura como acontece na aposentadoria.
Essa pesquisa aborda o tema da aposentadoria por uma perspectiva ocupacional e permite reforçar a importância do histórico ocupacional como referência organizadora do cotidiano no período da aposentadoria, bem como referência de significados ocupacionais construídos no percurso de vida. Por outro lado, os resultados ainda evidenciaram a possibilidade de desenvolvimento de novas ocupações, indicando que esse momento também pode ser visto como tempo de abertura para o novo.

As escolhas metodológicas deste estudo não incluíram diferenciações quanto ao gênero e classe social e tais aspectos poderão ser abordados em estudos futuros, enriquecendo a análise do processo de reorganização das ocupações na aposentadoria.

\section{CONSIDERAÇÕES FINAIS}

O estudo em questão revela que as ocupações realizadas no percurso de vida se tornam referências importantes no momento em que o sujeito precisa criar um novo arranjo ocupacional na aposentadoria. Observou-se que os entrevistados deram continuidade a muitas ocupações realizadas na fase laboral após a ruptura com o trabalho. Continuidade esta que aconteceu de diferentes formas, quer seja pela manutenção da ocupação, pela permanência do significado nela embutido ou, ainda, pelo resgate de uma ocupação interrompida. As experiências de continuidade apareceram com grande intensidade e relevância neste estudo.

Encontrou-se, também, a realização de novas ocupações não planejadas ou imaginadas pelos aposentados, comprovando que esse momento vai além da manutenção de referências passadas. Surge a novidade, indicando a possibilidade de abertura da vida e o potencial de desenvolvimento constante. $\mathrm{O}$ momento da aposentadoria também pode ser tempo de crescimento e desenvolvimento pessoal, de novos aprendizados e aquisições.

Espera-se que esse estudo possa contribuir para profissionais que atuam no atendimento de indivíduos aposentados e em programas de preparação para a aposentadoria, reconhecendo a história ocupacional como uma fonte relevante para orientações que visem o estabelecimento de novos arranjos ocupacionais que favoreçam a adaptação a essa nova fase da vida. No entanto, trata-se de uma pesquisa que não incluiu diferenciações quanto ao gênero e classe social e tais aspectos poderão ser abordados em estudos futuros. 


\section{REFERÊNCIAS}

1. Baltes PB, Smith J. Lifespan Psychology: from developmental contextualism to developmental biocultural co-construtivism. Res Hum Dev. 2004;1(3):123-44. http://dx.doi.org/10.1207/ s15427617rhd0103_1.

2. Christiansen C, Townsend E. Introduction to occupation: the art and science of living. Upper Saddle River: Pearson Education; 2009.

3. American Occupational Therapy Association (AOTA). Estrutura da prática da Terapia Ocupacional: domínio \& processo - 3a ed. traduzida. Rev Ter Ocup Univ São Paulo. 2015;26 (ed. esp.):149. doi: http://dx.doi.org/10.11606/issn.2238-6149.v26iespp1-49.

4. Arendt H. A condição humana. 10a ed. São Paulo: Editora Forense Universitária; 1991.

5. Souza RF, Matias HA, Brêtas ACP. Reflexões sobre envelhecimento e trabalho. Cienc Saude Coletiva. 2010;15(6):2835-43. http://dx.doi.org/10.1590/S141381232010000600021 .

6. Moreira JO. Imaginários sobre aposentadoria, trabalho, velhice: estudo de caso com professores universitários. Psicol Estud. 2011;16(4):541-50. http://www.scielo.br/scielo.php?script=sci arttext\&pid $=$ S1413-73722011000400005

7. Lancman S, Barros JO, Jardim TA. Teorias e práticas de retorno e permanência no trabalho: elementos para a atuação dos terapeutas ocupacionais. Rev Ter Ocup Univ São Paulo. 2016;27(2):101-8. doi: http://dx.doi.org/10.11606/issn.2238-6149.v27i2p101-108.

8. Alvarado I, Huerta APL, Díaz CAO, González VAVG, Waleska K. Jubilación: câmbios percebidos em relación a rutinas y roles en adultos mayores no institucionalizados de la ciudad de Punta Arenas. Rev Chilena Ter Ocup. 2012;12(1):1-10. doi: 10.5354/0717-5346.2012.22053.

9. Jonsson H, Josephsson S, Kielhofner G. Narratives and experience in a occupational transition: a longitudinal study of the retirement process. Am J Occup Ther. 2001;55(4):424-32. doi:10.5014/ajot.55.4.424.

10. Canizares JCL, Jacob Filho W. Fatores de risco à senilidade na transição à aposentadoria. Rev Bras Geriatr Gerontol. 2011;14(3):425-32. Disponível em: http://www.scielo.br/pdf/ rbgg/v14n3/v14n3a03.

11. Rodríguez GH. Cese de la actividad profesional y preparación para la jubilación. Cuad Relaciones Laborales. 2009;27(2):63-81. Disponível em: http://revistas.ucm.es/index.php/CRLA/article/ view/CRLA0909220063A/32229.

12. Jonsson H, Kielhofner G, Borell L. Antecipating retirement: the formation of narratives concerning an occupational transition. Am J Occup Ther. 1997;51(1):49-56. doi: 10.5014/ajot.51.1.49.
13. Wang M, Shi J. Psychological research on retirement. Annu Rev Psychol. 2014;65:209-33. doi: 10.1146/annurevpsych-010213-115131.

14. Zanelli JC. Processos Psicossociais, bem-estar e estresse na aposentadoria. Rev Psicol Organ Trab. 2012;12(3):329-40. Disponível em: http://pepsic.bvsalud.org/pdf/rpot/v12n3/ v12n3a07.pdf.

15. Jonsson H. The First steps into the third age: the retirement process from a Swedish perspective. Occup Ther Int. 2010;18(1):32-8. doi: 10.1002/oti.311.

16. Jonsson H. A new direction in the conceptualization and categorization of occupation. J Occup Sci. 2008;15(1):3-8. doi: 10.1080/14427591.2008.9686601

17. Jonsson H, Borell L, Sadlo G. Retirement: an occupational transition with consequences for temporality, balance and meaning of occupations. J Occup Sci. 2000;7(1):29-37. DOI: $10.1080 / 14427591.2000 .9686462$

18. Robson C. Real world research. 2a ed. Oxford: Blackwell Publishing; 2002.

19. Duarte CV, Melo-Silva LL. Expectativas diante da aposentadoria: Um estudo de acompanhamento em momento de transição. Rev Bras Orientac Prof. 2009;10(1):45-54. Disponível em: http://pepsic.bvsalud.org/scielo.php?script=sci arttext\&pid=S1679-33902009000100007.

20. Minayo MC. O desafio do conhecimento. 10a ed. São Paulo: Hucitec; 2010.

21. Zanelli JC, Silva N. Programa de preparação para aposentadoria. Florianópolis: Insular; 1996.

22. Paulin GST, Oliveira ML. Terapia Ocupacional no processo de envelhecimento e aposentadoria: construção de espaços saudáveis. Mundo Saúde (São Paulo). 2009;33(2):246-52. Disponível em: https://www.saocamilo-sp.br/pdf/mundo saude/67/246a252.pdf.

23. Pettican AR, Prior S. 'It's a new way of life': an exploration of the occupational transition of retirement. Br J Occup Ther. 2011;74(1):12-9. doi: 10.4276/030802211X12947686093521.

24. Silva MGS. Idosos aposentados: representações do cotidiano. Est Interdiscipl Envelhec. 1999;1:91-104. Disponível em: http://www.seer.ufrgs.br/index.php/RevEnvelhecer/article/ view/4655/2570.

25. Baltes PB, Lindenberger U, Staudinger UM. Life span theory in developmental psychology. In Lerner RM, Damon W. Handbook of child psychology: theoretical models of human development, v.1. 5a ed. New York: Wiley; 1998. p.1029-43.

Recebido em: 30.11 .2016

Aceito em: 27.07.2017 